\title{
Empirical Research On Coal Enterprise Executing Evaluation
}

\author{
Jing LIU \\ Henan college of industry and information technology, Jiaozuo Henan PRC \\ mxrsc@163.com
}

Key words: Method of fuzzy analytic hierarchy process; Coal enterprise; Execution; Evaluation

Abstract: Based on the analysis of the constituent elements and influence factors of the execution of the coal enterprise, using the basic principle of fuzzy analytic hierarchy process, this article try to set up a series of evaluation index system and evaluation model for measuring coal enterprise execution. The feasibility of this method is verified by examples, so as to provide theoretical basis for coal enterprises to improve execution.

\section{Introduction}

By the highlight attention of the party and the country, the coal mine safety production gradually improved, the mortality of coal mining and one million tons declined year by year. However, the safety production situation still severe, the major casualty cannot be controlled effectively and fundamentally. The author thinks that the main problem is that the enterprise managers and operators' execution has a lot difference and not enough in carrying out the national laws, regulations, enterprise management system and safety technical measures. Therefore, how to assess execution of coal mining enterprises reasonably, take protective measures effectively, make scientific management plans and supervision measures to reduce the coal mine accident probability and loss the rate of the accident has very important practical significance.

\section{Steps of using fuzzy analytic hierarchy process to evaluate the execution of coal enterprise}

\section{Establish evaluation index system and hierarchy of coal mine enterprise execution}

Execution of coal mining enterprises refers to the organizations at all levels of coal mining enterprises' ability to carry out the production safety guidelines, policies, laws and regulations, and technical standards made by the party and state, as well as the enterprise internal management system, safety technical measures. It's another leap in understanding of them ${ }^{[1]}$. Execution of coal enterprises is a comprehensive concept, involving all aspects of coal mining enterprises management and the structure itself is very complicated. According to the analysis of the coal mining enterprises execution, comprehensively considering the effectiveness and the purpose of evaluation, the evaluation habits and durability, the author built a three-tier classes hierarchy evaluation index system, including the executive process, the executive skills and the executive inclination of coal mining enterprises. Every indicator includes three specific indicators, a total of nine. Evaluation index system of coal mine enterprise' execution is shown in Fig.1 


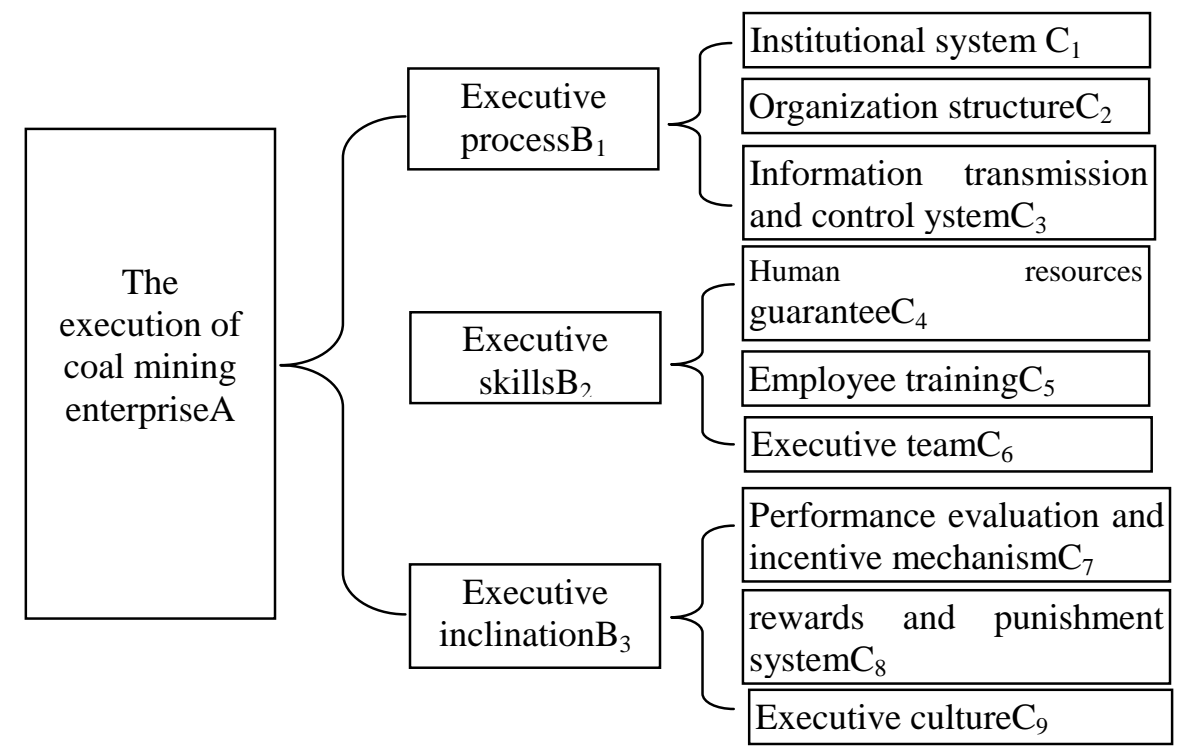

Fig.1 Evaluation index system of coal mine enterprise execution

\section{Construct the fuzzy complementary judgment matrix}

Fuzzy complementary judgment matrix $R$ refers an element of upper layer, Between this level and the relevant elements of comparison of the importance, assumptions on the level of the elements in the element to the next level, fuzzy consistent judgment matrix can be expressed as:

\begin{tabular}{l|llll}
$\mathrm{C}$ & $a_{1}$ & $a_{2}$ & $\ldots$ & $a_{n}$ \\
\hline$a_{1}$ & $r_{1}$ & $r_{1}$ & $\ldots$ & $r_{1}$ \\
& 1 & 2 & & $n$ \\
$a_{2}$ & $r_{2}$ & $r_{2}$ & $\ldots$ & $r_{2}$ \\
& 1 & 2 & & $n$ \\
$\ldots$ & $\ldots$ & $\ldots$ & $\ldots$ & $\ldots$ \\
$a_{n}$ & $r_{n}$ & $r_{n}$ & $\ldots$ & $r_{u}$ \\
& 1 & 2 & & $n$
\end{tabular}

$r_{i j}$ actual meaning is: element $a_{i}$ and element $a_{j}$. When comparing relative to the element, have "to a much more" membership degree of fuzzy relations. According to the scale, element relative to a layer, element of fuzzy judgment matrix can be obtained as follows:

$$
R=\left[\begin{array}{cccc}
r_{11} & r_{12} & \cdots & r_{1 n} \\
r_{21} & r_{22} & \cdots & r_{2 n} \\
\cdots & \cdots & \cdots & \cdots \\
r_{n 1} & r_{n 2} & \cdots & r_{n n}
\end{array}\right]
$$

$R$ Has the following properties:
(1) $r_{i i}=0.5, \quad i=1,2, \cdots, n$;
(2) $, \quad i=1,2, \cdots, n ; j=1,2, \cdots, n$;

In order to determine the element $a_{i}$ relative to $a_{j}$ importance, need to build one0.1-0.9The fuzzy judgment ${ }^{[2]}$. In this article, the author sent out the form of expert assessment on execution ability of coal mining enterprises to five experts from a large coal mining enterprises in Henan province. After experts filled in according to their professional knowledge and work practice, $r_{i j}=1-r_{j i}$ Form the fuzzy complementary judgment matrix. Such as by the execution of coal mining enterprises, five experts give the relative important degree of the matrix of the:

$$
R_{1}=\left[\begin{array}{lll}
0.5 & 0.4 & 0.4 \\
0.6 & 0.5 & 0.4 \\
0.4 & 0.6 & 0.5
\end{array}\right] \quad R_{2}=\left[\begin{array}{lll}
0.5 & 0.4 & 0.3 \\
0.6 & 0.5 & 0.4 \\
0.7 & 0.6 & 0.5
\end{array}\right] \quad R_{3}=\left[\begin{array}{lll}
0.5 & 0.3 & 0.4 \\
0.7 & 0.5 & 0.4 \\
0.6 & 0.6 & 0.5
\end{array}\right] \quad R_{4}=\left[\begin{array}{lll}
0.5 & 0.4 & 0.4 \\
0.6 & 0.5 & 0.4 \\
0.4 & 0.6 & 0.5
\end{array}\right]
$$




$$
R_{5}=\left[\begin{array}{lll}
0.5 & 0.3 & 0.3 \\
0.7 & 0.5 & 0.5 \\
0.7 & 0.5 & 0.5
\end{array}\right]
$$

\section{The fuzzy complementary judgment matrix into a fuzzy consistent matrix}

According to the formula when available $r_{i}=\sum_{k=1}^{n} r_{i k}, \quad(i=1,2, \cdots, n)$ and $b_{i j}=\frac{r_{i}-r_{j}}{2(n-1)}+0.5^{[3]}$, Fuzzy consistent matrix can be obtained $A_{i}$ （ $i$ is $i$ expert）。

$$
\begin{gathered}
A_{1}=\left[\begin{array}{ccc}
0.5 & 0.45 & 0.45 \\
0.55 & 0.5 & 0.5 \\
0.55 & 0.5 & 0.5
\end{array}\right] A_{2}=\left[\begin{array}{ccc}
0.5 & 0.425 & 0.35 \\
0.575 & 0.5 & 0.425 \\
0.65 & 0.575 & 0.5
\end{array}\right] \quad A_{3}=\left[\begin{array}{ccc}
0.5 & 0.4 & 0.375 \\
0.6 & 0.5 & 0.475 \\
0.625 & 0.525 & 0.5
\end{array}\right] \\
A_{4}=\left[\begin{array}{ccc}
0.5 & 0.45 & 0.45 \\
0.55 & 0.5 & 0.5 \\
0.55 & 0.5 & 0.5
\end{array}\right] \quad A_{4}=\left[\begin{array}{ccc}
0.5 & 0.425 & 0.425 \\
0.575 & 0.5 & 0.5 \\
0.575 & 0.5 & 0.5
\end{array}\right]
\end{gathered}
$$

\section{Relative weight calculation of sheer level indicators}

As the five experts score at the same time, in accordance with the formula : $r_{i}^{(l)}=\sum_{k=1}^{n} r_{i k}^{(l)}, \quad i=1,2, \cdots, n ; \quad l=1,2, \cdots, s^{[3]}$,

And the following mathematical transformation: $b_{i j}^{(l)}=\frac{r_{i}^{(l)}-r_{j}^{(l)}}{2(n-1)}+0.5, \quad l=1,2, \cdots, s$, get fuzzy consistent matrix $A=\left(b_{i j}^{(l)}\right)_{n \times n}(l=1,2, \cdots, s)$, and formula a fuzzy consistent matrix $\bar{A}=\left(\bar{b}_{i j}\right)_{n \times n}$, , $\bar{b}_{i j}=\sum_{l=1}^{s} \lambda_{l} b_{i j}^{(l)}, \lambda_{l}>0, \sum_{l=1}^{s} \lambda_{l}=1^{[4]}$, And you can know this matrix is also fuzzy consistency matrix, among $\lambda_{1}=\lambda_{2}=\lambda_{3}=\lambda_{4}=\lambda_{5}=0.2$ 。

$$
\bar{A}=\left[\begin{array}{ccc}
0.5 & 0.43 & 0.41 \\
0.57 & 0.5 & 0.48 \\
0.59 & 0.52 & 0.5
\end{array}\right]
$$

According to the formula $\omega_{i}=\frac{\sum_{l=1}^{s} \sum_{j=1}^{n} \lambda_{l} b_{i j}^{(l)}+\frac{n}{2}-1}{n(n-1)}, \quad i=1,2, \cdots, n$, get the relative weights of the indexes in matrix $\omega_{i}$, as shown in Table 1 。

Table 1 By the coal enterprise execution of judgment matrix

\begin{tabular}{ccccc}
\hline Coal enterprise execution & $\mathrm{B} 1$ & $\mathrm{~B} 2$ & $\mathrm{~B} 3$ & $\omega_{i}$ \\
\hline executive processB1 & 0.5 & 0.43 & 0.41 & 0.307 \\
executive skillsB2 & 0.57 & 0.5 & 0.48 & 0.342 \\
executive inclinationB3 & 0.59 & 0.52 & 0.5 & 0.351 \\
$w_{\text {准则层 }}=\left(\begin{array}{lllll}0.307 & 0.342 & 0.351\end{array}\right)^{T}$ & & & &
\end{tabular}

Other various levels $\omega_{i}$ calculate method as same as above.

\section{To calculate comprehensive weight}

Calculate a set of indicators to the adjacent layer on the relative weights, in accordance with the membership of each evaluation, result in synthesis weights of index evaluation relative to the total target. The basic calculation process in the following formula are available:

$v_{i j}=\omega_{i} \cdot \omega_{i j}, \quad i=1,2, \cdots, n ; j=1,2, \cdots, n$

Among: $v_{i j}$ for the lower comprehensive evaluation index weight; $\omega_{i}$ is the relative weight of the 
upper level indicators; $\omega_{i j}$ is for the relative weight of lower index.

According to the above formula, to calculate coal enterprise evaluation index system of execution of integrated weight as shown in Table 2.

Table 2 the evaluation index system of coal enterprise execution of integrated weight

\begin{tabular}{|c|c|c|c|}
\hline $\begin{array}{l}\text { The target } \\
\text { layer }\end{array}$ & Rule layer & Index layer & $\begin{array}{l}\text { The } \\
\text { comprehensive } \\
\text { weights } W\end{array}$ \\
\hline \multirow{9}{*}{$\begin{array}{l}\text { Execution of } \\
\text { coal mining } \\
\text { enterprises }\end{array}$} & \multirow{3}{*}{$\begin{array}{c}\text { Executive } \\
\text { process } 0.307\end{array}$} & system0.298 & 0.091 \\
\hline & & $\begin{array}{l}\text { organization } \\
\text { structure } 0.324\end{array}$ & 0.099 \\
\hline & & $\begin{array}{c}\text { Information } \\
\text { transmission and control } \\
\text { system } 0.378\end{array}$ & 0.116 \\
\hline & \multirow{3}{*}{$\begin{array}{l}\text { Executive } \\
\text { skills0.342 }\end{array}$} & $\begin{array}{l}\text { human resource } \\
\text { guarantee } 0.331\end{array}$ & 0.113 \\
\hline & & Employee training0.307 & 0.105 \\
\hline & & Executive team 0.362 & 0.124 \\
\hline & \multirow{3}{*}{$\begin{array}{c}\text { Executive } \\
\text { inclination } 0.35 \\
1\end{array}$} & $\begin{array}{l}\text { Performance evaluation } \\
\text { and incentive } \\
\text { mechanism0.342 }\end{array}$ & 0.12 \\
\hline & & $\begin{array}{l}\text { rewards and punishment } \\
\text { system } 0.316\end{array}$ & 0.112 \\
\hline & & $\begin{array}{c}\text { Enterprise executive } \\
\text { culture } 0.342\end{array}$ & 0.12 \\
\hline
\end{tabular}

\section{Examples of application}

The author chose a coal group of a mine as evaluation objects, using the fuzzy analytic hierarchy process to evaluate the execution of the mine. In order to evaluate the enterprise's execution objectively, the author give out the index score table to the mine ore level cadres, middle-level cadres and grassroots workers representative, let them give grade to the nine indicators of the execution influencing coal mining enterprises, score values range is $[0,10]$, The author sent out 60 score table, 58 was taken back. By calculating the arithmetic mean of every execution index, get nine indexes of value as shown in Table 3.

Table 3 execution index of one coal enterprise

\begin{tabular}{cccccccccc}
\hline index & $\mathrm{C}_{1}$ & $\mathrm{C}_{2}$ & $\mathrm{C}_{3}$ & $\mathrm{C}_{4}$ & $\mathrm{C}_{5}$ & $\mathrm{C}_{6}$ & $\mathrm{C}_{7}$ & $\mathrm{C}_{8}$ & $\mathrm{C}_{9}$ \\
\hline $\begin{array}{l}\text { index } \\
\text { value }\end{array}$ & 9.215 & 8.760 & 7.561 & 9.124 & 6.386 & 6.529 & 8.943 & 9.236 & 7.069 \\
\hline
\end{tabular}

The execution of the coal enterprise is $A=C \cdot W^{T}=8.041$ 。

In order to well explain the execution level of the coal mining enterprises, author set that when $A \in[1,0.9)$, states that the execution of coal enterprise is very strong; When $A \in[0.9,0.8)$, states that the execution of coal enterprise is strong; When $A \in[0.8,0.7)$, states that the execution of coal enterprise is general ; When $A \in[0.7,0]$, states that the execution of coal enterprise is weak.

The score of the enterprise execution is 8.041. In the interval of $[0.9,0.8)$, states that the execution of coal enterprise is strong.

In the survey, the author found that enterprise culture, the executive team and staff training are the main reason for enterprise execution of reaching a high level. Therefore, the enterprise should take measures from the three aspects to improve the execution. 


\section{Conclusion}

Executive ability is a vague concept. It is difficult to carry on quantitative evaluation. This article try to provide a more systematic and comprehensive method for the coal mining enterprises comprehensive evaluation of the execution by using the combination of qualitative and quantitative, expert review and the precise fuzzy hierarchy analysis method of complement each other, and to make the hierarchical analysis and fuzzy evaluation model. This method not only applied to the horizontal comparison of the coal mining enterprises execution, but also applied to the longitudinal comparison of the execution of the coal mining enterprises.

\section{References}

[1] Zhang Fuyou. Build first-class executive force is the key to realize the coal mine safety production [J]. Journal of Coal Mine Safety ,2007(1):55-56

[2] Saaty T L.The Analytic Hierarchy Process[M]. New York: McGraw - Hill, 1980

[3] Xu Zeshui. A kind of algorithm of fuzzy complementary judgment matrix sorting[J]. Journal of Systems Engineering ,2001.16(4):311-314

[4] Gui Huangbao,Zhao Fumin. Based on fuzzy analytic hierarchy process of cooperative partner selection of technical innovation research [J]. Science and Technology Management ,2007(9):50-54 